\title{
Percepções da Influência da Universidade Federal do Pampa na Formação de Capital Social na Região de Fronteira Santana do Livramento-Rivera
}

\author{
Deivid Forgiarini ${ }^{1}$ \\ Cinara Neumann Alves ${ }^{2}$ \\ Paulo Cassanego Junior ${ }^{3}$
}

\begin{abstract}
Resumo: Este estudo intenta identificar percepções acerca da influência da Universidade Federal do Pampa, Campus Santana do Livramento, na formação de capital social na fronteira Santana do Livramento/Rivera, entre 2006 e 2012, posto que a Lei no 11.640 reforça, como sendo objetivo da criação daquela Universidade, promover o desenvolvimento regional. A análise partiu de um resgate histórico que, em relação a dados sociais atuais, possibilitou identificar que a sociedade fronteiriça se encontra, ainda, estratificada, e, neste contexto, a geração de capital social constituir-se-ia um meio para a promoção do desenvolvimento regional. Através de estudo de caso com triangulação de fontes de dados, obtiveram-se percepções de atores sociais relevantes, internos e externos à Universidade, que estiveram presentes durante os seis primeiros anos de instalação da Instituição. Os principais resultados apontam a UNIPAMPA como instituição relevante para o desenvolvimento regional, porém não promotora do aumento de capital social.
\end{abstract}

Palavras-chave: Universidade Federal. Capital Social. Desenvolvimento Regional.

Abstract: This study intends to identify perceptions about influence of Federal University of Pampa, Campus Santana do Livramento, in social capital formation in Santana do Livramento/Rivera border region, between years 2006 and 2012. The Brazilian Law no 11.640 reinforces, as being an objective of the creation of UNIPAMPA, the promotion of regional development. Analysis starting from a historical research that, in relation with social current data, made possible to identify that the society is still stratificated, and, in this context, the generation of social capital would be one of the ways for promotion of regional development. Through a case study, there were obtained perceptions of social relevant actors, those were present in the region during the first six years of installation of UNIPAMPA. The principal results shows that UNIPAMPA is a relevant institution for the regional development, however still not being a social capital promoter.

Keywords: Federal University. Social Capital. Regional Development.

\section{Introdução}

O presente estudo teve como foco buscar compreender a ação da Universidade Federal do Pampa (UNIPAMPA), sob a perspectiva da formação de capital social,

\footnotetext{
${ }^{1}$ Doutorando no Programa de Pós-Graduação em Administração da Unisinos. Professor da ESCOOP - Faculdade de Tecnologia do Cooperativismo e da UniRitter. deividforgiarini@gmail.com

2 Doutoranda no Programa de Pós-Graduação em Desenvolvimento Regional da UNISC. Professora da ESCOOP Faculdade de Tecnologia do Cooperativismo. cinaranalves@gmail.com

${ }^{3}$ Doutor em Administração. Professor da Universidade Federal do Pampa. paulo.cass@gmail.com
} 
particularmente a partir da atuação da Universidade na fronteira Santana do Livramento (Brasil) e Rivera (Uruguai). Parte-se de um resgate histórico, em que se evidencia a formação da estrutura social desta fronteira desde o século XVI até o final do século XIX, dando destaque à formação de duas classes sociais bem consolidadas: os que possuem terras e os que não possuem terras (TORRONTEGUY, 1994). Esta base histórica valoriza as disputas territoriais entre as coroas portuguesa e espanhola pela região do Pampa gaúcho e tem, no advento do Uti possidetis e na dotação das sesmarias, um importante marco para sua concentração fundiária. Este resgate histórico acaba não se atendo, no entanto, às importantes transformações do século $X X$, uma vez que se entende que essas transformações pouco alteraram a estrutura fundiária da região e apenas reforçaram atividades econômicas de ciclo curto (ALONSO; BANDEIRA; BENETTI, 1994). Dados mais recentes evidenciam tal concentração fundiária nessa região fronteiriça, bem como a busca por um esforço de articulação entre tal concentração e os índices sociais abaixo das médias nacionais brasileiras, já reconhecidos pelos governos federal e estadual.

Diante deste quadro, no contexto do presente estudo, o capital social é definido como um dos meios possíveis de promoção do desenvolvimento regional nessa sociedade aparentemente estratificada do ponto de vista social (oriunda de uma igual estratificação fundiária). A implantação da UNIPAMPA, destarte, consistiria em uma das ações para reverter esses índices sociais abaixo da média, como defende seu próprio projeto institucional (UNIPAMPA, 2009ạ; 2009b) e sua Lei de criação, a Lei 11.640/08 (BRASIL, 2008). Neste sentido, a partir dos atores (internos e externos à Instituição) envolvidos nos seis primeiros anos da implantação da Universidade, buscou-se acolher suas próprias percepções acerca da formação de capital social na região e do papel da Universidade nesse processo.

Assim, com vistas a captar e compreender tais percepções, buscou-se, primeiramente, definir, para este estudo, o que seria capital social, bem como o que se entende da relação entre universidade e desenvolvimento regional. Partindo de tal entendimento, conduziu-se um estudo de caso com triangulação de fontes de dados (documentos, dados secundários, formulários e observação participante), cujos resultados foram assim estruturados neste artigo: a) apresentação de dados referentes à formação socioeconômica da fronteira Santana do Livramento (Brasil) e Rivera (Uruguai); b) contextualização histórica e caracterização da Universidade Federal do Pampa - UNIPAMPA; e c) percepção, por 
diferentes atores pesquisados, acerca da formação de capital social na região fronteiriça e possível influência da UNIPAMPA neste contexto. O artigo é concluído com considerações finais e sugestões para estudos futuros.

\section{Fundamentos teóricos}

\subsection{Conceituando Capital Social}

Na definição de Woolcock (1998), capital social abrange as normas e as redes que facilitam o trabalho coletivo. Mantém-se, assim, nesta pesquisa, o foco mais nas redes e não nas normas, pois se entende que as normas só se mantêm em uma rede bem forte e estruturada. De forma complementar, a definição de Putnam (1994) e as associações horizontais também são úteis à compreensão do conceito.

Para Putnam (1994), os valores cívicos apoiariam a formação do espírito cooperativo de forma cíclica, fortalecendo a associação e um ciclo virtuoso. Cabe ressaltar que, para Putnam, essas associações eram feitas em relações horizontais, e não verticais, sem hierarquia, sem barreiras de entrada, fortalecendo os laços de contato entre o grupo, pensando, então, a comunidade em associações com agentes com status e poder equivalentes (PUTNAM, 1994).

Coleman e Granovetter trazem mais contribuições quando relacionam capital social com as redes sociais. Granovetter (1985) lança "Economic Action and the Social Structure: the problem of embeddedness" ("Ação Econômica e Estrutura Social: o problema da imersão"), onde critica os dois lados da economia, a neoclássica e a aquela que privilegia o meio, de forma a determinar a ação das pessoas. Para superar essa discussão, propõe uma análise em que o indivíduo esteja envolto em uma rede de relações sociais, o que, em outras palavras, quer dizer que as pessoas adotam suas decisões, mas observam o ambiente em que se encontram e as redes sociais em que estão inseridas.

Nesse ambiente de redes, a cooperação é incentivada, e a reputação de cada um também, e, assim, o grupo entra em um ambiente de ciclo virtuoso. Afirma o mesmo autor que as questões de confiança - e até mesmo a organização da atividade econômica precisam ser examinadas com a lente da rede social (GRANOVETTER, 1985). Neste ínterim, é 
que se insere Coleman. Coleman é o responsável por dar visibilidade ao conceito de capital social e colocá-lo no circuito em que, logo depois, Putnam irá desenvolver o mesmo conceito em seu trabalho publicado em 1993 na Itália. Coleman, em suas obras (COLEMAN, 1988; 1990), mantém uma estreita relação com Granovetter e define capital social como uma variedade de entidades que têm o mesmo aspecto de uma estrutura social e facilitam ações dos indivíduos dentro dessa estrutura. Neste contexto, como outras formas de capital, o capital social é produtivo, permitindo a realização de certos fins que não seriam atingíveis na sua ausência. Porém, diferentemente de outras formas de capital, o capital social interfere na estrutura de relações interpessoais, não se localizando nem no indivíduo nem em instrumentos físicos da produção (COLEMAN, 1990).

A forma como Coleman define capital social, com um viés para produção, mostra como as relações podem incentivar esta produção. Explica o sentido do termo capital, por que algo que é produtivo explica o social, por que se cria nas relações, afirmando que não é uma coisa única, mas várias, que têm em comum o fato de estarem em uma estrutura e facilitarem as relações entre pessoas. Mostra, assim, que o capital social não é tangível, de forma que ele não seria formalmente "apresentado" às pessoas e às coisas, dado que ele existe nas relações das pessoas, ou seja, sem relações, não há capital social.

Com base neste entendimento de capital social, buscou-se, de forma a operacionalizar a pesquisa aqui pretendida, um instrumento já validado e utilizado para sua mensuração. Neste sentido, definiu-se, como base para o estudo, a escolha do "Questionário Integrado para Medir Capital Social (QI-MCS)". Este questionário foi elaborado pelo Banco Mundial, em 2003, e também tem inspiração em Woolcock (1998). Foram definidas seis dimensões, que são as seguintes: Grupos e Redes; Confiança e Solidariedade; Ação Coletiva e Cooperação; Informação e Comunicação; Coesão e Inclusão Social; Autoridade (ou capacitação) (Empowerment) e Ação Política. O Banco Mundial (WORLD BANK, 2003) explana a importância de cada dimensão, conforme se vê abaixo.

1) Grupos e Redes: segundo o Banco Mundial, normalmente esta dimensão é a que mais as pessoas relacionam com capital social, discutindo-se os vários tipos de organização de que possam fazer parte e as contribuições dadas e recebidas, bem como a liderança destes grupos e a sua diversidade. 
2) Confiança e Solidariedade: destaca a confiança entre as pessoas, bem como a solidariedade entre as pessoas da localidade escolhida.

3) Ação Coletiva e Cooperação: investiga como se dá o trabalho entre as pessoas da comunidade, se conseguem e como trabalham em conjunto ou mesmo como em resposta a alguma crise, tal como as consequências do não-cumprimento das expectativas em relação à participação.

4) Informação e Comunicação: cada vez mais o acesso à informação é importante para que as comunidades periféricas possam ter voz ativa para alcançarem os objetivos para o seu bem-estar. Por isso, é fundamental que estas comunidades estejam conectadas com tudo o que ocorre ao seu redor.

5) Coesão e Inclusão Social: as comunidades acabam sendo antes caracterizadas mais pela sua coesão do que pelas suas diferenças. Esta dimensão busca identificar a natureza e o tamanho de tais diferenças e como são geridas.

6) Autoridade (ou capacitação) (Empowerment) e Ação Política: para o Banco Mundial, os indivíduos têm mais liberdade e são mais capacitados quando têm mais controle sobre as questões e as instituições que afetam diretamente o seu bem-estar, por isso esta dimensão busca investigar como as pessoas se sentem quanto à sua capacidade de definir suas vidas e como veem a política de sua localidade.

\subsection{Universidade e desenvolvimento (Regional)}

Mais do que uma proposta empresarial, o pensamento liberal busca criar aos países latino-americanos um sistema educacional adequado às expectativas exógenas no que pese o incentivo à formação de pessoas para funções pouco complexas e que não sejam libertadoras no pensar (SEVERINO, 2008).

Essa é uma condição complicada, porque tal proposição evidencia as diferenças entre os países do centro e da periferia do capitalismo, na medida em que a produção de conhecimento, a concepção e a disseminação de novas tecnologias, fatores imperativos para o desenvolvimento no contexto contemporâneo, e que dependem essencialmente de investimento em pesquisa e de uma formação educacional intensa, ficam sob o domínio das 
nações centrais. Romero e Calderano (2008) afirmam que não foi o conhecimento o elemento central das reformas educacionais.

Deste modo, a magnitude que deveria estar contemplada no conceito de formação afunda-se em um pragmatismo no qual é confirmada a conversão em valor econômico de todos os elementos que compõem a sociedade. Neste ínterim, a cidadania, a ética, a política e a história seriam esquecidas, ou deixadas de lado, assim como o incentivo à reflexão e ao pensamento crítico (VOGT, 2003).

Por outro lado, propõe-se a construção de uma matriz tecnológica identificada com as questões nacionais e regionais, que compreenda e responda às necessidades da população. Desta forma, a relação com o aporte tecnológico, dentro da premissa de atender tanto aos anseios locais quanto à necessidade de colocação no contexto internacional, adquire outros atributos, na medida em que surgem reflexões sobre sua implementação. Há, nesse cenário, a aproximação entre ciência e cidadania, partindo da preocupação constante em refletir sobre a relevância das inovações tecnológicas para a resolução dos problemas sociais, direcionando a pesquisa e seus resultados para toda a sociedade (ROMERO; CALDERANO, 2008).

\section{Procedimentos metodológicos}

A pesquisa realizada pode ser considerada quali-quantitativa, constituindo um estudo de caso com triangulação de fontes de dados (YIN, 2001), valendo-se de documentação, análise de dados secundários, aplicação de formulário e observação participante.

A documentação resume-se, essencialmente, à legislação relacionada à Universidade, sua criação e propósitos; a análise de dados secundários resume-se ao levantamento de dados socioeconômicos da região da fronteira, junto a institutos e órgãos de estatística nacionais nos dois países que compõem a região de fronteira Santana do Livramento Rivera (Brasil e Uruguai), particularmente envolvendo as informações de concentração de renda, NBIs e estrutura fundiária. A aplicação de formulário, por seu turno, realizou-se junto a gestores da Universidade, além de acadêmicos, docentes e atores sociais do governo e da comunidade. A observação participante deu-se por parte de um dos pesquisadores, que foi acadêmico de graduação da instituição durante todo o período analisado. Os dados 
secundários e os obtidos por meio dos formulários foram analisados por uma estatística descritiva simples, e suas análises foram complementadas pelas observações do pesquisador participante e por dados documentais.

Antes de se iniciar a coleta de dados, que ocorreu entre os meses de maio e outubro de 2013, envolvendo gestores da Universidade, acadêmicos, docentes e atores sociais do governo e da comunidade, realizou-se uma primeira abordagem com cada pesquisado, garantindo-se o anonimato e o uso dos dados de forma global.

Tendo-se o formulário como principal instrumento de pesquisa, a escolha dos pesquisados seguiu os critérios da intencionalidade e da acessibilidade (GIL, 1999), em que o pesquisador seleciona os sujeitos que possam ser considerados representativos da população, aos quais, concomitantemente, ele possa ter acesso facilitado. O formulário foi elaborado tendo como base o instrumento original proposto pelo Banco Mundial (WORLD BANK, 2003).

Foram escolhidos oito grupos de respondentes para a aplicação do formulário: quatro internos à Universidade e quatro externos a ela. Os grupos internos envolvem: 1 . docentes; 2. técnicos administrativos em educação - TAEs; 3. terceirizados; e 4. discentes. 0 critério adotado foi a escolha de pessoas que estivessem constituindo seu grupo desde 2006 até 2012, já que assim se poderia obter uma "fotografia" viável da percepção de cada um em cada um destes dois momentos, com a mesma pessoa evidenciando suas percepções em cada momento histórico por ela vivido nesse processo. Nesta busca, descobriu-se que, coincidentemente, permaneceram vinculados à Instituição dois docentes, dois TAEs e dois terceirizados. Seguindo esta lógica de representantes por classe, também participaram do estudo dois discentes que estavam na mesma situação, ou seja, de discentes do campus Santana do Livramento da UNIPAMPA desde 2006 até 2012.

Já os grupos externos, também quatro, envolveram 1. o poder executivo, compreendendo um representante do governo municipal de Santana do Livramento e um do governo de Rivera, ambos tendo ocupado cargos de destaque no período analisado; 2. membros de clubes de serviços e associações; 3. líderes comunitários (por indisponibilidade de vários representantes do lado uruguaio, o formulário foi aplicado a apenas um respondente do lado brasileiro); e 4. o poder legislativo, em que, de igual forma, por indisponibilidade e dificuldade de acesso de representantes do lado uruguaio, foi possível 
realizar a pesquisa apenas com um representante brasileiro, vereador em Santana do Livramento, que se manteve no cargo durante todo o período entre os anos de 2006 e 2012.

Assim, foram ao todo quatorze respondentes, divididos em oito grupos, sendo que quatro destes grupos estavam diretamente ligados à UNIPAMPA, e os outros quatro ligados à sociedade em geral. Para os grupos que tiveram mais de um representante, foi feita uma média simples entre a opinião de seus representantes. $\mathrm{O}$ instrumento utilizado foi elaborado com base no Questionário Integrado para Medir Capital Social - QI-MCS - (WORLD BANK, 2003), e considerando as seis dimensões de Capital Social já mencionadas anteriormente. Foram selecionadas quatro perguntas de cada dimensão. Estas perguntas foram transformadas em afirmações, e foi possibilitado a cada pesquisado que indicasse se ele "discorda completamente", informando o número 1 (um); "discorda", informando o número 2 (dois); "concorda", informando o número 3 (três); ou, finalmente, "concorda completamente", informando o número 4 (quatro). As afirmações foram formuladas de forma que as respostas tendendo a 1 (um) indicassem falta de capital social, e as tendendo a 4 (quatro) indicassem alto nível de capital social. Assim, nos resultados, o valor 1 (um) é indicação para baixo nível; 2,5 (dois e meio), de nível médio; e 4 (quatro), de alto nível.

A apresentação dos resultados, portanto, considerou os seguintes critérios: a) a percepção de desenvolvimento de capital social em 2006 por todos os atores; b) a percepção do desenvolvimento de capital social em 2012 por todos os atores; e c) a percepção da influência da UNIPAMPA neste processo.

\section{Discussão e análise dos resultados: a formação de capital social na fronteira Santana do Livramento (Brasil) e Rivera (Uruguai) e a UNIPAMPA}

4.1 Um breve resgate histórico: a formação socioeconômica da fronteira Santana do Livramento (Brasil) e Rivera (Uruguai)

A região do Pampa Gaúcho foi disputada desde meados do século XVI, quando ainda fazia parte do território espanhol, com base no Tratado de Tordesilhas, do final do século XV, que teve a influência direta da Bula do Papa Alexandre VI; todavia, a mesma Igreja Católica, dois séculos depois, cria um bispado no Rio de Janeiro com "jurisdição" até as margens do Rio da Prata, abrangendo todo o território do atual Uruguai (PINTOS, 2008). 
Portugal desejava este território por ser a rota espanhola por onde escoava a extração de metais preciosos oriundos da região andina, e por ser também rota para o interior da América como um todo. Mais tarde, depois do abandono das missões jesuíticas (devido aos incessantes ataques dos bandeirantes), o gado criado nessa região acaba vagando e encontra nas pastagens do Pampa as condições ideais para procriação, gerando, assim, um grande ativo econômico: a Vacaria del Mar (ABELLA, 2008; PACHECO; SANGUINETTI, 1985; PINTOS, 2008; TORRONTEGUY, 1994).

Num primeiro momento, Portugal funda, ao final do século XVII, a Colônia de Sacramento, que acaba sendo um grande entreposto comercial e pivô de inúmeros conflitos entre as coroas, passando de um lado para o outro inúmeras vezes, em iguais inúmeros tratados. No século XVIII, consolidada a importância econômica da região conhecida como Vacaria del Mar, Colônia de Sacramento acaba tendo ainda mais destaque, e o seu domínio reflete a força momentânea de cada coroa.

A questão dos limites territoriais nas Américas vai ganhando espaço na agenda diplomática dessas coroas, proporcionalmente aos transtornos que vão gerando a ambas. Dom João VI tem como objetivo dar um fim a estes conflitos, e, depois do insucesso de uma série de diplomatas, indica Alexandre de Gusmão para a função (RIO BRANCO; MARIZ, 2010).

Nascido no Brasil Colônia, Alexandre teve como diferencial o fato de ter um conhecimento amplo do Brasil e, mesmo antes de trabalhar nesta negociação, já ter enviado casais portugueses da Ilha de Açores para colonizarem o atual Estado do Rio Grande do Sul e, assim, garantirem estas possessões portuguesas (PINTOS, 2008). Em 1750, este diplomata surpreende ao ceder a cobiçada Colônia de Sacramento. Esta cedência desconcerta os espanhóis: deveria haver uma compensação. Em troca, a Espanha cederia os territórios pouco explorados e povoados que hoje formam o norte e o centro-oeste do Brasil, e, ainda, aceitaria a inclusão da cláusula do Uti possidetis no direito internacional público. Ou seja, o usucapião deixava de ser apenas do Direito Civil e passava a pertencer ao Direito Internacional Público (RIO BRANCO; MARIZ, 2010).

Com isso, o processo de dotação de sesmarias na região da Vacaria del Mar consistiuse numa forma de financiamento privado para o domínio português de um importante ativo econômico: o charque, importante para um Brasil que se integrava economicamente em 
função da extração de ouro nas Minas Gerais, no centro do país, já que os escravos que trabalhavam em tais extrações necessitavam ser alimentados (PESAVENTO, 1980).

A necessidade de dominar essa região vai fazendo com que ela seja cortada por sesmarias. Tais sesmarias são doadas a militares e nobres próximos à Coroa portuguesa. Neste momento, surge um novo comandante, tanto militar como econômico: o proprietário da sesmaria torna-se a "lei" em sua propriedade. Para o gaúcho, el gaucho, não resta outra opção: ou cai na marginalidade, ou é abrigado em uma das sesmarias da região (a legalidade só existia dentro das sesmarias) e "[...] ser um desafeto de um estancieiro significava correr risco de vida (TORRONTEGUY, 1994, p. 57)".

Os conflitos entre as Coroas vão crescendo, e do lado espanhol iniciam-se os movimentos pela independência da região administrativa denominada Vice-Reinado do Prata, que abarcava os atuais territórios da Argentina, Uruguai e Paraguai, predominantemente (PACHECO; SANGUINETTI, 1985). Contudo, em razão das inúmeras frentes de batalha e do crescimento do apoio popular que o General Artigas recebia na banda oriental, o governo central do Vice-Reinado do Prata deixou este general à própria sorte, quando a elite de Montevideo solicitou apoio à Coroa Portuguesa, que usou deste pretexto para anexar a Província Cisplatina (ABELLA, 2008; PACHECO; SANGUINETTI, 1985; PINTOS, 2008). Para o governo do Vice-Reinado já mencionado, era uma frente de batalha a menos e a certeza de poder se concentrar em outras frentes. Para os orientais, foi a certeza que "no eran ni serian jamás argentinos ni brasileños" (NAHUM, 2008, p. 17).

Os uruguaios conseguem sua independência em 1828. É definido, porém não confirmado, o Rio Quaraí como limite natural. Esta independência do Uruguai afeta diretamente a elite charqueadora de Pelotas, que fica sem a matéria-prima vinda do Pampa, agora que boa parte dele é território uruguaio. Em 1835, surge a Revolução Farroupilha, uma revolução feita pelas elites que desejavam ter seus mercados (no centro do Brasil) protegidos do charque platino (TORRONTEGUY, 1994). Em 1845, a Revolução é encerrada com a promessa do governo brasileiro de apoiar a elite gaúcha. Essa promessa é cumprida em 1851, quando o governo brasileiro, ao oferecer apoio ao Partido Colorado e definir de fato as fronteiras entre Brasil e Uruguai, impõe uma série de sanções ao governo uruguaio, sanções estas que acabam privilegiando a elite charqueadora gaúcha (PACHECO; SANGUINETTI, 1985; PESAVENTO, 1985; PINTOS, 2008; TORRONTEGUY, 1994). 
Em 1850, tem-se o advento da Lei de Terras (BRASIL, 1850), que dá poder legal às sesmarias, e, nas décadas seguintes, o cercamento dos campos obriga, por fim, o gaúcho a escolher entre a criminalidade e o servir em uma propriedade. A bravura que o fez lutar nos inúmeros conflitos, ou mesmo o trabalho com afinco como peão nos tempos de paz, não lhe resultou numa ascensão social, apenas um efêmero prestígio social, um reconhecimento paliativo dos proprietários de terras, que, ao mantê-las sob o seu domínio, acabaram cristalizando uma estrutura social marcadamente estratificada entre os possuidores de terra e os não-possuidores de terra (TORRONTEGUY, 1994).

Dados mais recentes retratam justamente tal panorama histórico. A análise de dados obtidos junto ao Instituto Brasileiro de Geografia e Estatística (2006) confirma que a estrutura fundiária na fronteira, do lado de Santana do Livramento, apresenta apenas 7\% de suas propriedades com mais de 1000 hectares, enquanto o outro lado possui $93 \%$ de suas propriedades com área inferior a 1000 hectares (47\% têm área de 20 a 99 hectares). Já com relação à área efetivamente ocupada, a maior ocupação ocorre nas propriedades que possuem entre 1000 e 2499 hectares (37\% de área ocupada).

Do lado de Rivera, observa-se a presença de dados semelhantes (embora os dados sejam um tanto mais recentes, obtidos junto ao Ministerio de Ganadería Agricultura \& Pesca, Republica Oriental del Uruguay (2011): 9\% das propriedades possuem mais de 1000 hectares, e 91\%, menos de 1000 hectares. Em todas as propriedades, os maiores percentuais de área ocupada encontram-se também nas áreas com mais de 1000 hectares $(22 \%$ nas áreas entre 1000, e 2499 hectares e 38\% nas áreas com mais de 2500 hectares).

A inferência trazida por este estudo é a de que tal concentração fundiária pode trazer reflexos aos índices sociais relacionados com a concentração de renda (Instituto Nacional de Estatistica del Uruguay, 2013): em todo o Uruguai, há regiões em que pelo menos $26,8 \%$ dos habitantes têm pelo menos uma necessidade básica insatisfeita (NBI), e, particularmente nas regiões ao norte do país, a população com pelo menos uma NBI é de até $54 \%$. Do lado de Santana do Livramento, os $20 \%$ mais ricos concentram $59,3 \%$ da renda, enquanto os $20 \%$ mais pobres concentram apenas $3,3 \%$.

A partir daí, acredita-se que estudos para o desenvolvimento desta região de fronteira poderiam ser mais frutíferos se fossem estudos coordenados de forma bilateral, já que ambas as regiões possuem as mesmas raízes históricas, estruturas fundiárias 
concentradas, o mesmo bioma Pampa e matrizes produtivas semelhantes, assim como as características culturais, compondo la cultura gaucha também. Ambos os lados estão distantes 500 quilômetros dos centros mais próximos de poder, com o lado brasileiro em situação inferior, pois a instância estadual de decisão é limitada no que tange ao regulamento judiciário, dependendo da geograficamente longínqua Brasília, no Distrito Federal.

Pode-se afirmar que ainda hoje há ressonâncias advindas das disputas territoriais nesta região. Seus problemas sociais evidenciam tal situação, aparentemente perpetuada pela estrutura fundiária que permanece. Seguindo a metodologia das NBIs (necessidades básicas não satisfeitas), a educação pode ser um fator de transformação entre gerações. Ações que quebrem os paradigmas atuais podem constituir um caminho viável para o desenvolvimento dessa região.

Identificar os produtos característicos desse território, agregar valor e desenvolver o trabalho coletivo, para o fortalecimento dessas cadeias de produtos identificados com essa cultura, em uma relação bilateral, podem ser caminhos para o desenvolvimento, no sentido mais amplo do conceito. Almeja-se que as antigas disputas territoriais, que fragmentaram o Pampa e que dividiram politicamente povos tão próximos culturalmente, sejam superadas. Supõe-se que isto possa se dar por meio da geração de capital social, e que uma universidade regional possa ter um papel relevante neste sentido.

\subsection{O Contexto da Universidade Federal do Pampa, sua história e caracterização}

Segundo o Plano Institucional da UNIPAMPA (UNIPAMPA, 2009a), a Universidade foi uma reivindicação da comunidade da região que convergiu com a política de desenvolvimento do ensino público superior que o governo brasileiro desenvolvia na época. Esta política entende que a expansão do ensino superior pode ser um meio de desenvolvimento regional, tal como a instalação desta Universidade na região do Pampa:

[...] veio marcada pela responsabilidade de contribuir com a região em que se edifica um extenso território, com críticos problemas de desenvolvimento socioeconômico, inclusive de acesso à educação básica e à educação superior - a 'metade sul' do Rio Grande do Sul (UNIPAMPA, 2009a, p. 4). 
Ainda, o documento afirma que a instituição veio com a intenção de aumentar a integração com os países que fazem fronteira com a região - Uruguai e Argentina. Em setembro de 2006, iniciaram-se as atividades da Universidade. Entre 2006 e 2008, houve um primeiro momento de implantação sob a coordenação da Universidade de Santa Maria e a da Universidade Federal de Pelotas, até que, em 11 de janeiro de 2008, a Lei no 11.640 (BRASIL, 2008) cria oficialmente a UNIPAMPA - Fundação Universidade Federal do Pampa -, segundo a qual (2009a, p. 4), “[...] a UNIPAMPA terá por objetivos ministrar ensino superior, desenvolver pesquisa nas diversas áreas do conhecimento e promover a extensão universitária, caracterizando sua inserção regional, mediante atuação multicampi na mesorregião Metade Sul do Rio Grande do Sul".

Dando posse à sua reitoria pró-tempore, define-se o profissional docente que atende aos desejos desta Instituição:

[...] um educador com elevada titulação, possuidor de uma formação acadêmica sólida e qualificada, dimensionada no conhecimento específico e nos estudos interdisciplinares da profissionalidade requerida. É comprometido com a integração do ensino, da pesquisa e da extensão, inserido na região do Pampa, em sua diversidade cultural, atuando como potencializador das relações socioeconômicas e do desenvolvimento sustentável (UNIPAMPA, 2009a, p. 5).

A Instituição compreende que, para ter sucesso neste empreendimento, deve ter amplo conhecimento da região em que está inserida, para superar as dificuldades encontradas, desenvolver as potencialidades e trabalhar com parcerias, sendo protagonista dessa aproximação entre os atores sociais. Destarte, sobre a concepção que tem de si:

[...] a concepção de universidade não se restringe apenas à formação profissionalizante, mas se firma em uma proposição humanística e generalista, assumindo o compromisso com o direito à vida e promovendo a ética em todas as suas práticas. Ao mesmo tempo, olhar a Universidade, a partir das comunidades nas quais ela está inserida, pressupõe que os sujeitos implicados nas suas ações a percebam como parte integrante da vida social, comprometendo-a, por conseguinte, com o desenvolvimento regional sustentável (UNIPAMPA, 2009A, p. 7).

Por isso mesmo:

[...] nessa direção, a Universidade não pode ser um espaço meramente reprodutivo do saber acumulado pela humanidade nem tampouco o educando pode ser tomado como um receptor passivo deste saber. A Instituição precisa traduzir os desafios de seu tempo, revisar o que está posto e ter a coragem da utopia por um mundo melhor. Ela deve apostar no trabalho colaborativo (...) (UNIPAMPA, 2009a, p. 9). 
Os caminhos tanto da Universidade como da região serão definidos pela capacidade dos seus diversos atores de pensarem desta forma, ainda que sem perder o foco principal da Instituição: “formar sujeitos da sua própria história” (UNIPAMPA, 2009a, p.10).

Seguem nesta mesma linha os Princípios Balizadores (valores), a Missão e a Visão da Universidade, conforme o seu Projeto Institucional (UNIPAMPA, 2009a):

\section{a) Princípios balizadores}

[...] Sentido público, manifesto por sua gestão democrática, gratuidade e intencionalidade da formação e da produção do conhecimento, orientado pelo compromisso com o desenvolvimento regional para a construção de uma Nação justa e democrática.

\section{b) Missão}

A Universidade Federal do Pampa, como instituição social comprometida com a ética, fundada em liberdade, no respeito à diferença e na solidariedade, assume a missão de promover a educação superior de qualidade, com vistas à formação de sujeitos comprometidos e capacitados a atuar em prol do desenvolvimento sustentável da região e do país.

\section{c) Visão}

Constituir-se como instituição acadêmica de reconhecida excelência, integrada e comprometida com o desenvolvimento sustentável da região e do país.

Percebe-se aí a intenção dos gestores da Universidade, em sua implantação, de que esta exercesse uma função catalisadora, promotora do desenvolvimento regional, função que este estudo buscou verificar na prática.

4.3 A formação de capital social e a UNIPAMPA como agente catalisador do desenvolvimento regional na fronteira Santana do Livramento - Rivera

São, neste momento, apresentadas as percepções dos atores relevantes, participantes da pesquisa, acerca da formação do capital social na fronteira Santana do Livramento-Rivera, bem como suas percepções sobre uma possível relação entre a formação 
de capital social e a atuação da UNIPAMPA como agente catalisador do desenvolvimento regional na fronteira palco da pesquisa.

Inicialmente, apresenta-se a Tabela 1, contendo as médias, por dimensão do instrumento, das percepções do total de atores sociais pesquisados. Conforme já apresentado nos procedimentos metodológicos, o instrumento utilizado foi elaborado com base no Questionário Integrado para Medir Capital Social - QI-MCS - (WORLD BANK, 2003), e nas seis dimensões dele constantes: ação coletiva e cooperação; grupos e redes; confiança e solidariedade; informação e comunicação; coesão e inclusão social; e autoridade e ação política. Em cada dimensão, quatro perguntas foram selecionadas e transformadas em afirmações, permitindo que cada pesquisado indicasse se ele "discorda completamente", informando o número 1 (um); "discorda", informando o número 2 (dois); "concorda", informando o número 3 (três); ou "concorda completamente", informando o número 4 (quatro). As afirmações foram formuladas de forma que as respostas tendendo a 1 (um) indicassem falta de capital social, e as tendendo a 4 (quatro) indicassem alto nível de capital social.

A apresentação dos resultados, portanto, considerou: a) a percepção de desenvolvimento de capital social em 2006, por todos os atores; b) a percepção do desenvolvimento de capital social em 2012, por todos os atores; e c) a percepção da influência da UNIPAMPA neste processo. Nos resultados, o valor 1 (um) é indicação para baixo nível; 2,5 (dois e meio), de nível médio; e 4 (quatro), de alto nível. 
Tabela 1 - Percepção dos atores sociais por dimensão/ capital social e influência da UNIPAMPA

\begin{tabular}{|c|c|c|c|}
\hline Blocos & $\begin{array}{c}\text { Percepção } \\
\text { em } 2006\end{array}$ & $\begin{array}{c}\text { Percepção } \\
\text { em } 2012 \\
\end{array}$ & $\begin{array}{c}\text { Influência da } \\
\text { UNIPAMPA }\end{array}$ \\
\hline $\begin{array}{l}\text { Ação coletiva } \\
\text { e cooperação }\end{array}$ & 2,22 & 2,45 & 2,19 \\
\hline Grupos & & & \\
\hline redes & 2,27 & 3,02 & 2,2 \\
\hline $\begin{array}{l}\text { Confiança e } \\
\text { solidariedade }\end{array}$ & 2,11 & 2,31 & 1,94 \\
\hline $\begin{array}{l}\text { Informação e } \\
\text { comunicação }\end{array}$ & 2,92 & 3,34 & 2,09 \\
\hline $\begin{array}{l}\text { Coesão } \\
\text { inclusão } \\
\text { social }\end{array}$ & 2,3 & 2,5 & 1,98 \\
\hline $\begin{array}{l}\text { Autoridade e } \\
\text { ação política }\end{array}$ & 2,38 & 3,02 & 2,5 \\
\hline Geral & 2,36 & 2,77 & 2,15 \\
\hline
\end{tabular}

Fonte: Dados da pesquisa (2013).

Na Tabela 1, alguns dados em especial podem ser considerados relevantes. Pode ser alvo de atenção, por exemplo, o fato de que a dimensão em que, aparentemente, a influência da Unipampa é maior foi a dimensão "autoridade e ação política". Tal dimensão, segundo o Banco Mundial (WORLD BANK, 2003), refere-se ao empowerment ou "empoderamento", isto é, a uma possível interferência das pessoas na vida política local, tendo mais controle sobre as questões e as instituições que afetam diretamente o seu bemestar.

Em outras palavras, pode-se inferir que a instalação da Unipampa na fronteira Santana do Livramento-Rivera, na percepção desses sujeitos, tem média interferência no empoderamento local de grupos e indivíduos. Logo, em segundo lugar, a dimensão "grupos e redes", bastante relacionada com capital social, apresenta resultado intermediário entre o nível baixo e o médio $(2,2)$, seguida, na mesma linha, do resultado da dimensão "ação coletiva e cooperação", relacionada à participação das pessoas em comunidade $(2,19)$. Nas demais dimensões, contudo, todos os resultados são realmente baixos, indicando uma percepção de pouca ou muito pouca influência da Unipampa na formação de capital social. A média geral de todas as dimensões, na percepção da influência da Universidade, segue na mesma tendência, apresentando resultado relativamente baixo $(2,15)$. 
Os Gráficos 1 e 2, por seu turno, apresentam, em separado, dados referentes às percepções gerais, dos grupos de atores internos e externos à Unipampa, respectivamente, tanto acerca da percepção geral sobre a evolução do capital social, nos anos 2006 e 2012, quanto com relação à influência da UNIPAMPA neste processo.

\section{Gráfico 1 - Percepção da influência da UNIPAMPA/ atores do público interno à UNIPAMPA}

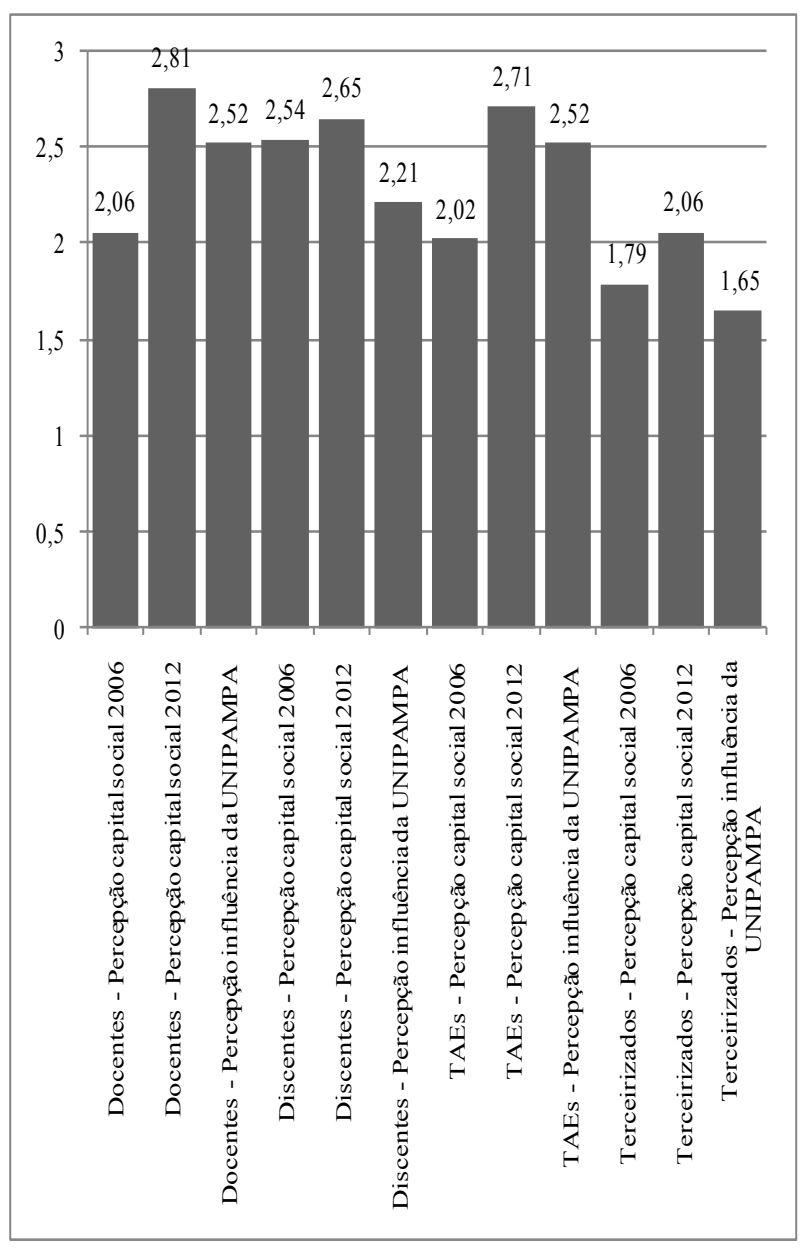

Fonte: Dados da pesquisa (2013).

Conforme o Gráfico 1, no que tange às percepções dos atores internos pesquisados, docentes e técnicos administrativos - TAEs - essas percepções (sobre a influência da Unipampa na formação de capital social) estão praticamente no limiar entre o nível baixo e o nível médio (2,52 em ambos). As percepções dos outros dois grupos de atores internos (discentes e terceirizados) são ainda mais baixas: 2,21 e 1,65, respectivamente. Uma inferência possível, e que aponta para possibilidades de estudos futuros, é a de que, por 
vezes, o envolvimento de estudantes e terceirizados é de caráter temporário, até mesmo porque vários alunos da Universidade, mesmo tendo permanecido entre 2006 e 2012 na Instituição, podem não possuir um envolvimento maior com as questões de desenvolvimento local e regional, isto é, não serem, necessariamente, oriundos e/ou residentes na fronteira Santana do Livramento/Rivera, e/ou nem todos ainda disporem de elementos suficientes para refletir sobre a Universidade para além de seu papel de promotora do ensino, da pesquisa e da extensão.

\section{Gráfico 2 - Percepção da influência da UNIPAMPA/ atores do público externo à UNIPAMPA}

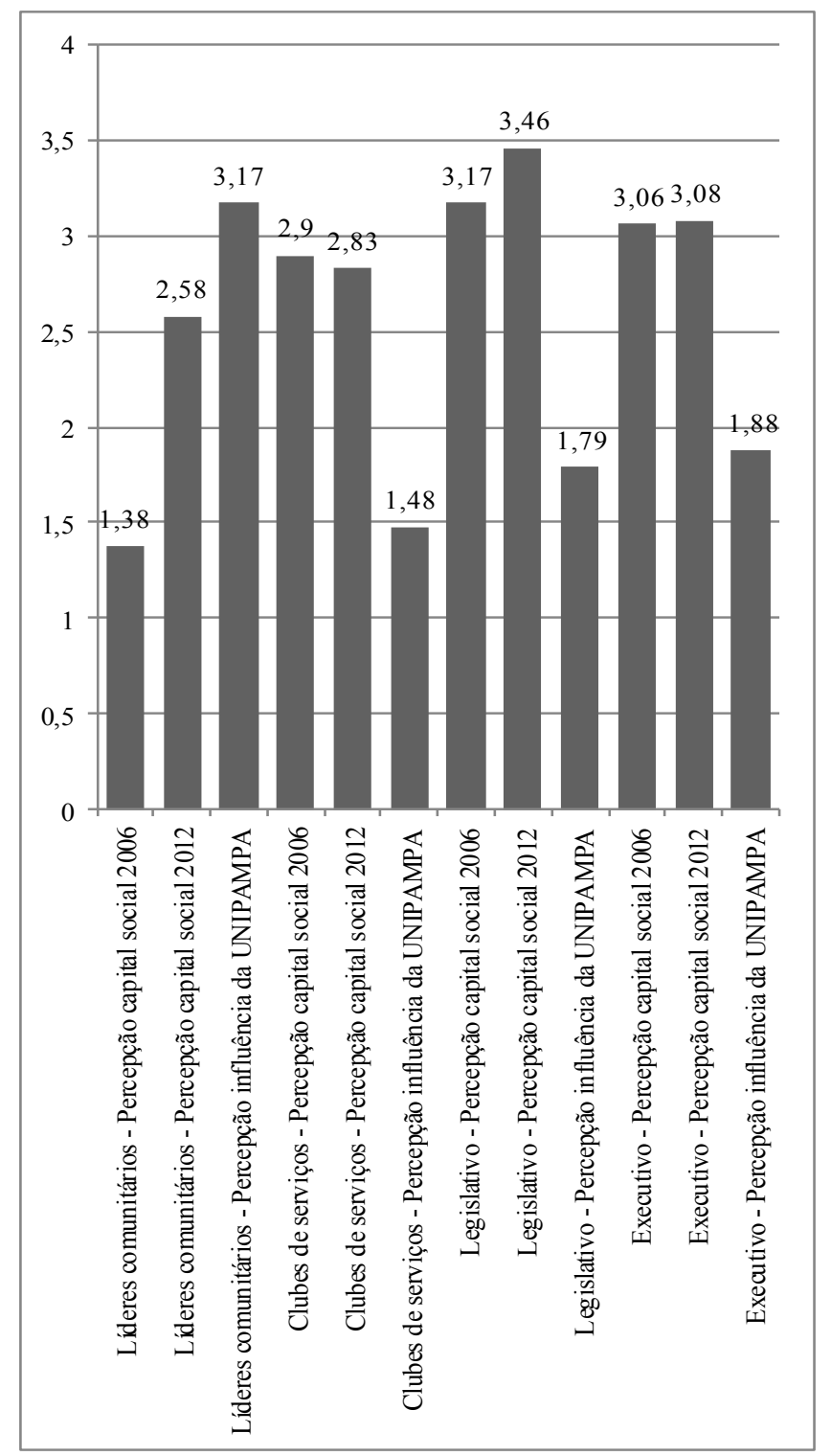

Fonte: Dados da pesquisa (2013). 
De acordo com o apresentado no Gráfico 2 - exceto para o grupo de líderes comunitários, para o qual a UNIPAMPA teve grande influência -, todos os demais atores sociais externos possuem uma percepção baixa ou muito baixa da influência da Universidade na geração de capital social (abaixo de 1,90). Uma inferência possível é a de que líderes comunitários teriam uma maior proximidade das ações desenvolvidas pela Universidade em comparação com outros atores. Este, possivelmente, seria um indicativo da necessidade de melhor análise sobre as ações de extensão da Instituição e como vêm sendo percebidas por diferentes segmentos sociais.

\section{Gráfico 3 - Percepção geral da influência da UNIPAMPA na formação de capital social}

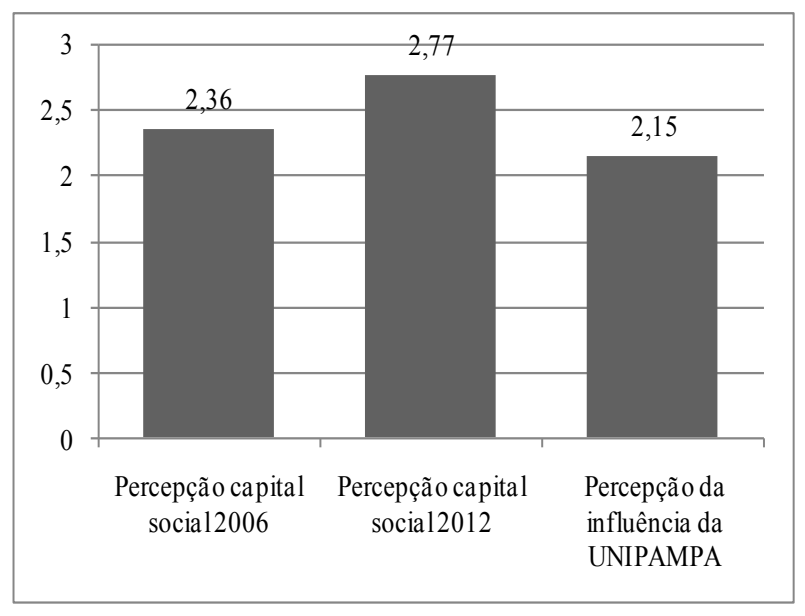

Fonte: Dados da pesquisa (2013).

Por fim, analisando-se o Gráfico 3, que mostra a percepção geral de todos os atores acerca da formação de capital social e da influência da UNIPAMPA neste processo, pode-se afirmar que foi observado um crescimento, entre 2006 e 2012, dessa percepção no que se refere à formação de capital social, todavia esse crescimento não parece estar diretamente relacionado com a UNIPAMPA. Os atores sociais a veem como um fator catalisador de desenvolvimento regional, e não efetivamente como um ator protagonista do desenvolvimento regional, conforme sua lei e projeto institucional pretendiam.

A UNIPAMPA, aparentemente, não consegue desenvolver com efetividade ações com o outro lado da fronteira (o uruguaio), mesmo que este esteja a apenas poucos metros de seu endereço físico. O que se supõe, portanto, é que cabe à Universidade assumir a 
responsabilidade para a qual foi criada, indo além da mera criação de um conhecimento tecnicista, com foco apenas na inserção no mercado de trabalho. Esta Instituição, além da formação e da construção de saberes, tem como função o apoio ao desenvolvimento regional, no entanto este não será efetivo se a UNIPAMPA mantiver apenas um papel catalisador, sem se envolver com o processo de transformação social por meio das atividades de ensino, pesquisa e extensão.

A partir da pesquisa realizada, pode-se inferir brevemente que a Universidade acaba se eximindo de seu papel de protagonista na transformação social dessa fronteira, com vistas ao desenvolvimento regional. Ela contribuiu pelo simples fato de estar ali presente, mas não porque de fato interfere no dia a dia fronteiriço, pelo menos não na percepção dos atores sociais pesquisados.

\section{Considerações finais}

A região do Pampa Gaúcho, conforme já ressaltado, foi construída historicamente na segregação de classes. Entretanto, dada a habilidade da elite local, essa segregação foi suavizada com o uso da recompensa em prestígio social, recompensa que não era traduzida em capital, em renda, em possibilidade de mudança social. Isso criou uma sociedade estratificada: os possuidores de terras e os não possuidores de terra.

Pela pesquisa como um todo, mas sobretudo pela aplicação dos formulários, notouse que a sociedade em geral tem suas expectativas frustradas em relação à Universidade. Isso, porém, não pode ser responsabilidade apenas da administração local, que apenas implementa as decisões conjuntamente decididas hoje no CONSUNI (Conselho Universitário) da UNIPAMPA (UNIPAMPA, 2009b). Isso não exime a possibilidade da administração local de ser mais proativa, mas a sua margem de manobra pode ser pequena. É necessária uma revisão administrativa geral da organização.

O fato de a Instituição ser considerada de recente criação (menos de 10 anos) foi, também, o que incentivou a realização da pesquisa, para que ainda se possa propor intervenções nesse sentido. Uma possível limitação da pesquisa, contudo, foi o envolvimento apenas de sujeitos que estiveram presentes nos últimos 6 anos junto à Instituição, o que pode ter acarretado vieses interpretativos. De qualquer forma, a partir 
desta primeira pesquisa, lançou-se um olhar que permitiu avaliar a formação histórica de grupos sociais excluídos, mensurar o capital social dessa fronteira e analisar a participação da Universidade, que, ao menos em tese, surgiu para contribuir para o desenvolvimento regional do Pampa. Uma outra limitação da pesquisa envolve a impossibilidade de realização de entrevistas em profundidade, que poderiam ampliar o escopo de dados analisados, complementando ou mesmo confrontando os resultados apresentados pela aplicação do formulário. Esta seria a principal sugestão para um estudo futuro, tanto no contexto da UNIPAMPA quanto no contexto de outras Universidades em regiões fronteiriças.

Ademais, trabalhar apenas com percepções dos atores oferece uma visão, por vezes, particular da realidade, que poderia ser complementada ou contraposta a, por exemplo, indicadores quantitativos que pudessem ser relacionados à formação de capital social. Ainda, alguns aspectos que foram inferidos a partir dos dados apresentados podem originar outras investigações, abrindo outras possibilidades de pesquisas futuras.

A despeito de tais limitações, entende-se que a pesquisa apresenta uma contribuição inicial para promover a discussão acerca do papel das Universidades no desenvolvimento regional. Por meio da promoção de um espaço amplo e democrático de construção conjunta de saberes, tais como a Universidade, pode-se encurtar as pontes e promover o trabalho coletivo e a cooperação, um dos meios para a promoção de efetivo desenvolvimento.

\section{Referências}

ABELLA, Gonzalo. Historia diferente del Uruguay: ensayo. Montevideo: BetumSan Ediciones, 2008.

ALONSO, José Antonio Fialho; BENETTI, Maria Domingues; BANDEIRA, Pedro Silveira. Crescimento econômico da Região Sul do Rio Grande do Sul: causas e perspectivas. Porto Alegre: Secretaria do Planejamento e da Administração - Fundação de Economia e Estatística Siegfried Emanuel Heuser (FEE), 1994.

COLEMAN, J. Foundations of Social Theory. Cambridge: Belknap Press of Harvard University Press, 1990.

Social capital in the creation of human capital. American journal of sociology, v. 94, p. 95-120, 1988. 
GIL, Antônio Carlos. Pesquisa social: métodos e técnicas. v. 5. São Paulo: Atlas, 1999.

GRANOVETTER, Mark. Economic action and social structure: The problem of embeddedness. American journal of sociology, v. 91, n. 3, p. 481-510, 1985.

INSTITUTO BRASILEIRO DE GEOGRAFIA E ESTATÍ́STICA. 2006. Censo Agropecuário de 2006. Disponível em: <http://www.ibge.gov.br/home/estatistica/economia/agropecuaria/ censoagro/default.shtm >. Acesso em: out./2015.

INSTITUTO NACIONAL DE ESTATISTICA DEL URUGUAY. 2013. Atlas Sociodemográfico y de la Desigualdad del Uruguay. Disponível em: <http://www.ine.gub.uy/biblioteca/Atlas_ Sociodemografico/Atlas_fasciculo_1_NBI_versionrevisada.pdf>. Acesso em: out./2015.

MINISTERIO DE GANADERÍA AGRICULTURA \& PESCA. Republica Oriental del Uruguay (2011). Censo General Agropecuario 2011. Disponível em: <http://www.mgap.gub.uy/portal/ hgxpp001.aspx?7,5,27,O,S,0,MNU;E;2;16;10;6;MNU>. Acesso em: out./2015.

NAHUM, Benjamín. Breve historia del Uruguay independiente. n. 989.9 NAH, 1999.

PACHECO, M. Schurmann; SANGUINETTI, María Luisa Coolighan. Historia del Uruguay: Epocas indígena, hispánica y libertadora. Montevideo: Monteverde, 1985.

PESAVENTO, Sandra Jatahy. História da indústria sul-rio-grandense. Rio Grande Companhia de Celouse do Sul, 1985.

. História do Rio Grande do Sul. Mercado Aberto, 1980.

PINTOS, Aníbal Barrios. Historia de los pueblos orientales: Del fin de la Guerra Grande al novecientos. Ediciones de la Banda Oriental, 2008.

PUTNAM, Robert D.; LEONARDI, Robert; NANETTI, Raffaella Y. Making democracy work: civic traditions in modern Italy. Princeton: University Press, 1994.

BRANCO RIO; MARIZ, Vasco. Alexandre de Gusmão e o Tratado de 1750/Miguel Paranhos Rio Branco; A tormentosa nomeação do jovem Rio Branco para o Itamaraty. Brasileira: FUNAG, 2010.

ROMERO, C. C.; CALDERANO, M. A. Dimensões econômicas e políticas da relação educação e trabalho nos países da América Latina e Caribe. Educação em Foco, v. 12, n. 2, p. 13-26, 2008.

SEVERINO, Antônio Joaquim. O ensino superior brasileiro: novas configurações e velhos desafios. Educar em revista, n. 31, 2008.

TORRONTEGUY, Teófilo Otoni Vasconcelos. As origens da pobreza no Rio Grande do Sul. Porto Alegre: Mercado Aberto, 1994. 
UNIPAMPA. Projeto Institucional. 2009a. Disponível em:

<http://www.unipampa.edu.br/portal/arquivos/PROJETO_INSTITUCIONAL_16_AG0_2009.pdf>. Acesso em: set./2015

UNIPAMPA. Instrução Normativa 08/09. 2009b. Disponível em:

<http://porteiras.r.unipampa.edu.br/portais/CONSUNI/resolucoes>. Acesso em: set./2015

VOGT, Carlos. O conhecimento, as universidades e seus desafios. Universidade em questão. Brasília: Universidade de Brasília, 2003.

WOOLCOCK, Michael. Social capital and economic development: Toward a theoretical synthesis and policy framework. Theory and society, v. 27, n. 2, p. 151-208, 1998.

WORLD BANK. Guatemala Poverty Assessment. Washington D. C.: World Bank, 2003.

YIN, R. K. Estudo de caso: planejamento e métodos. Porto Alegre: Bookman, 2001. 